\title{
Function of p21 and its therapeutic effects in esophageal cancer (Review)
}

\author{
LEI WANG* ${ }^{*}$ HUIQIONG HAN* ${ }^{*}$ LIN DONG, ZEHUA WANG and YANRU QIN \\ Department of Oncology, The First Affiliated Hospital of Zhengzhou University, Zhengzhou, Henan 450052, P.R. China
}

Received July 20, 2020; Accepted November 25, 2020

DOI: $10.3892 / \mathrm{ol} .2020 .12397$

\begin{abstract}
Esophageal cancer (EC) is the eighth most common type of cancer worldwide and ranks sixth among the causes of cancer-related mortality. Due to the high mortality rate and poor treatment efficacy for EC, millions of individuals succumb to this disease; thus, the identification of novel treatment targets is of utmost importance and urgency. In recent years, there have been advances if therapies targeting cell cycle regulators. p21 is a type of cell cycle regulator that plays a dual role in tumor cells, as it can not only regulate the cell cycle, induce apoptosis and inhibit cell proliferation, but can also protect cells from apoptosis. It has been found that $\mathrm{p} 21$ often exerts a tumor-suppressive effect on EC, which provides a basis for its use as a treatment target for EC. Therefore, the aim of the present study was to review the function of p21 and its potential value as a therapeutic target for EC.
\end{abstract}

\section{Contents}

1. Introduction

2. p21 regulates the cell cycle, DNA replication and apoptosis

3. p21 may be regulated through p53-dependent and -independent pathways

4. Role of p21 in the treatment of esophageal cancer

5. Conclusion

\section{Introduction}

According to the 2018 Global Cancer Statistics, the number of new cases of esophageal cancer (EC) in 2018 accounted

Correspondence to: Professor Yanru Qin, Department of Oncology, The First Affiliated Hospital of Zhengzhou University, 1 Jianshe East Road, Zhengzhou, Henan 450052, P.R. China

E-mail: yanruqin@zzu.edu.cn

*Contributed equally

Key words: p21, p53, esophageal cancer, targeted drugs, CDK4/6 inhibitors for $3.2 \%$ of the total number of cancer cases, with EC-related fatalities accounting for $5.3 \%$ of the total cancer deaths (1). There are two main histological types of EC, namely esophageal squamous cell carcinoma (ESCC) and esophageal adenocarcinoma (EADC). ESCC is the most common histological type of EC worldwide, particularly in high-risk areas, such as China. China is one of the areas exhibiting a high incidence of EC, which may be associated with genetics and lifestyle habits. Smoking, excessive alcohol consumption and the excessive intake of red meat and spicy foods are considered as high-risk factors for ESCC (2-4). Previous studies on EC cases in China, particularly in Linxian county, which has the highest ESCC-related mortality rate worldwide, demonstrated that a polymorphism in the TP53 gene (the main regulator of p21) is associated with the risk of developing $\operatorname{ESCC}(5,6)$. Intestinal metaplasia in Barrett's esophagus is a major risk factor for EADC, and the inactivation of p53 and p21 may be implicated in the progression of Barrett's esophagus to cancer $(7,8)$.

Radical surgery is the only curative method currently available for the treatment of EC; however, as the early symptoms of EC are not evident, the majority of patients are already at an advanced stage at the time of diagnosis. Radiotherapy and chemotherapy are the main treatment strategies for patients with advanced EC. However, chemotherapeutic resistance and adverse events may occur, which are the main causes of treatment failure in EC. Immunotherapy for EC has recently emerged; PD-1/PD-L1 inhibitors have been proven to be effective in the treatment of EC (9). Furthermore, angiogenesis inhibitors and inhibitors of epidermal growth factor receptor, such as bevacizumab, cetuximab, panitumumab and erlotinib, have been reported to be useful for the treatment of EC (10). However, only limited progress has been made in targeting drugs specific to EC. Therefore, the identification of novel therapeutic targets for EC is the focus of ensuing research.

It has been $>20$ years since p21 was discovered as a cell cycle inhibitor regulated by p53. In 1993, el-Deiry et al identified p21 by using subtractive hybridization technology, which is downstream of wild-type p53, a 21-kDa protein encoded by wild-type p53-activated fragment gene 1 (WAF1) (11). In addition, Harper et al demonstrated that p21 is a type of cyclin-dependent kinase (CDK) inhibitor through a two-hybrid system (12). In recent years, the therapeutic potential of targeting the cell cycle has been widely acknowledged. The new generation of selective CDK4/6 inhibitors, such as palbociclib, has been approved for the treatment of breast cancer (13). This 
has put forward a new approach to the treatment of EC via targeting the cell cycle.p21, as a cell cycle kinase inhibitor, can regulate cell cycle progression in EC (14). Subsequent research has identified that p21 also plays an important role in inducing cell senescence and apoptosis, promoting DNA repair and maintaining genome stability (15). Therefore, it is necessary to examine the role of p21 in EC and actively develop drugs targeting $\mathrm{p} 21$.

\section{2.p21 regulates the cell cycle, DNA replication and apoptosis}

p21 regulates the cell cycle by inhibiting the cyclin-CDK complex. Cyclin is a type of protein that is ubiquitous in eukaryotic cells and can appear and disappear regularly during the cell cycle (16). Cyclin regulates the cell cycle by binding to and activating CDK. As shown in Table I, the phosphorylation of specific targets by the cyclin-CDK complex sets in motion different processes that drive the cell cycle in a timely manner (17). Over the past two decades, numerous studies have demonstrated that cell cycle disorders are implicated in human cancers; the overactivation of CDK may promote tumor development by inducing unprogrammed cell division of stem or progenitor cells.

p21 is an effective CDK inhibitor that can bind to CDK and block the cell cycle (12). p21 can be combined with and inhibit almost every cyclin-CDK complex, such as cyclin D-CDK4, cyclin E-CDK2 and cyclin A-CDK2 (11). p21 inhibits the cyclin E-CDK2 complex, thereby inhibiting the phosphorylation of RB and the sequestration of E2F1 and arresting the cell cycle in the $G_{1}$ phase. p21 also inhibits the kinase activity of cyclin A-CDK1/2, which is necessary for entering the $\mathrm{G}_{2}$ phase through the $\mathrm{S}$ phase. In addition, p21 inhibits the kinase activity of cyclin B-CDK1, thereby inhibiting progression through the $\mathrm{G}_{2} / \mathrm{M}$ phase. Under certain conditions, p21 promotes the activity of CDK4 or CDK6, thereby promoting progression through the $G_{1}$ phase (18). The aforementioned findings indicate that $\mathrm{p} 21$ plays multiple roles in the regulation of the cell cycle. A summary of the role of p21 in cell cycle regulation by combining with different complexes is illustrated in Fig. 1.

p21 inhibits the binding of proliferating cell nuclear antigen (PCNA) to polymerase $\delta$ to affect DNA replication. The control of DNA replication is a key factor for maintaining normal cell function, as it can affect the stability of the genome. DNA replication that occurs in the $S$ phase of the cell cycle is essential for cell division (19). PCNA is an evolutionarily well-preserved protein that exists in all eukaryotes. PCNA was first found to be a processing factor for DNA polymerase $\delta$, which is required for DNA synthesis during replication (20). PCNA recognizes the primer-template junction and conjugates with replication factor $\mathrm{C}$ (RFC) to assist in the positioning of polymerase $\delta$, and it also strengthens the advancement of polymerase in the extension process.

Podust et al (21) found that p21 first inhibited the RFC-catalyzed loading of PCNA onto DNA and that, second, it prevented the binding of the DNA polymerase $\delta$ core to the PCNA clamp assembled on the DNA; the latter was the most potent inhibitory effect on polymerase $\delta$ enzyme activity. p21 can form a stable complex with PCNA on DNA, preventing further interaction with the replication proteins, RFC and DNA polymerase $\delta$ (22). In addition, Zhang et al (23) discovered the existence of PCNA-p21/cyclin-CDK quaternary complexes, which may be associated with the regulation of the cell cycle.

p21 can inhibit apoptosis by suppressing stress-activated protein kinase (SAPK) and apoptotic signal-regulated kinase 1 (ASK1). SAPK is a member of the subfamily of the mitogen-activated protein (MAP) kinases, which can be activated in response to DNA damage. During cellular stress, the $\mathrm{N}$-terminus of p21 binds to and inhibits the activity of SAPK, prevents c-Jun phosphorylation and Ap-1 activation, thus participating in the regulation of apoptosis. p21 located in the cytoplasm can interact with SAPK and ASK1 to inhibit their catalytic activity, thereby inhibiting apoptosis (24,25). ASK1, also known as MAP kinase 5 (MAP3K5), has the potential to induce cellular apoptosis under various physiological conditions. Zhan et al (26) demonstrated that p21 interacts with ASK1 and downregulates its kinase activity. These findings may indicate some of the mechanisms through which p21 inhibits apoptosis.

\section{3. p21 may be regulated through p53-dependent and -independent pathways}

p53-dependent pathway. Numerous studies have confirmed that p21 expression is dependent on p53 and performs part of the functions of p53 as its downstream mediator $(11,12,27,28)$. When cells are exposed to radiation and DNA damage occurs, p53 and p21 are often highly expressed in p53 wild-type cells, while p53-deficient cells usually do not exhibit a high p21 expression, and the cells do not undergo cell cycle arrest. At present, p21 is known as the cell cycle inhibitory protein with the most extensive kinase inhibitory activity. Amino acids 21-26 and 49-72 of p21 bind to cyclin and CDK, respectively, so that the kinase activity of cyclin-CDK complex is lost. In summary, when cells suffer DNA damage due to environmental stimuli, p21 can inhibit the activity of the cyclin-CDK complex as a CDK inhibitor through the p53-dependent pathway, so that $\mathrm{Rb}$ protein cannot be phosphorylated, thus arresting the cell cycle in the $\mathrm{G}_{1} / \mathrm{S}$ phase (11). In addition, it was previously demonstrated that p53 not only induces the expression of p21 and exerts a tumor-suppressive effect, but also plays a role by directly forming a complex with p21 $(29,30)$. For example, p53 and p21 can bind to Bcl-2 family proteins, such as Bcl-w and Bcl-xL, and release the Bax protein through the formation of the $\mathrm{p} 53 / \mathrm{p} 21 / \mathrm{Bcl}-\mathrm{w}$ complex to promote tumor cell apoptosis.

In EC cells, the p53/p21 pathway is also crucial for the regulation of cell proliferation. For example, researchers previously used mibefradil in EC cells to inhibit the function of calcium channels, and found that p21 increased in the p53-dependent pathway, which ultimately inhibited the proliferation of EC cells (31). In addition, SOX6, EC-related gene (ECRG)4, KLF4/5 and other genes were shown to regulate the proliferation of EC cells through the p53/p21 pathway (32-35).

\section{p53-independent pathway}

Transcriptional regulation of 221 . The regulation of $\mathrm{p} 21$ in cells is highly complex and diverse and p21 can also be regulated 


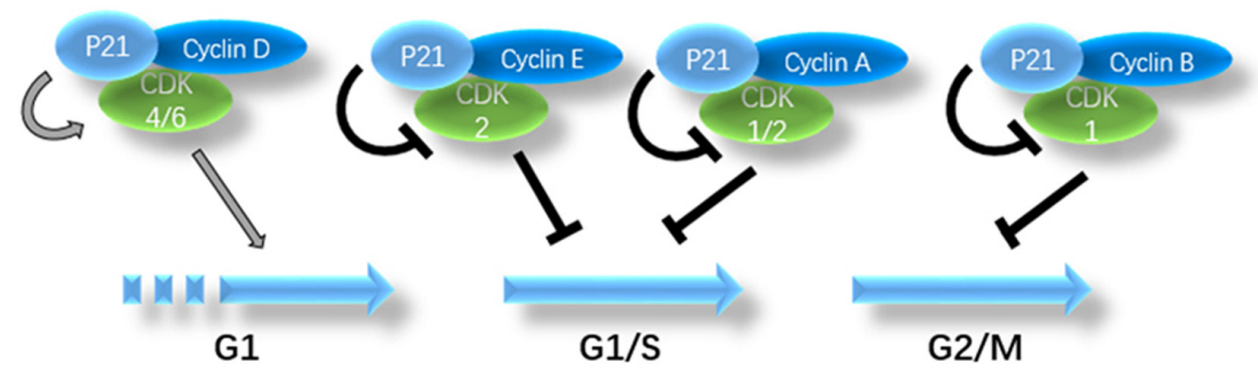

Figure 1. p21 combines with different cyclin-CDK complexes to exert its effects. CDK, cyclin-dependent kinase.

Table I. Cyclin-CDK complex can act at different times in the cell cycle.

\begin{tabular}{ll}
\hline Cell cycle & \multicolumn{1}{c}{ Cyclin-CDK complex } \\
\hline G1 phase & Cyclin D-CDK4, cyclin D-CDK6 \\
G1/S phase & Cyclin E-CDK2 \\
S phase & Cyclin E-CDK2, cyclin A-CDK1, \\
& cyclin A-CDK2 \\
G2/M phase & Cyclin B-CDK1
\end{tabular}

CDK, cyclin-dependent kinase.

through a p53-independent pathway. The Krüppel-associated box zinc-finger protein 545 (ZNF545) has been proven to directly regulate p21 independently of p53 (36). It was previously demonstrated that, in p53-mutant EC cell lines, the expression of ZNF545 upregulated the protein expression levels of the pivotal effectors, p21 and Bax, thereby inhibiting tumor cell proliferation and promoting apoptosis. Human riboflavin transporter 2 and ECRG1 have also been confirmed to directly regulate the expression of $\mathrm{p} 21$, thereby regulating the proliferation of EC cells $(37,38)$.

Post-transcriptional control of p21. p53 activates the transcription of p21 in the case of DNA damage and creates an unstable $\mathrm{p} 21$, the stability of which may improve by interacting with WISp39 and Hsp90. As previously demonstrated, p21 cannot be upregulated in response to DNA damage due to the lack of WISp39, suggesting that p21 transcriptional control is insufficient to upregulate p21 protein expression following DNA damage in the absence of p21 stability $(39,40)$. A 2018 study demonstrated that the loss of USP11 may cause p21 instability and induce $\mathrm{G}_{1} / \mathrm{S}$ transition in cells; in addition, the accumulation of p21 due to DNA damage was completely eliminated in cells lacking USP11, which led to the abolition of the $\mathrm{G}_{2}$ checkpoint and the induction of apoptosis (41). p21 is mainly degraded through the ubiquitination pathway (42). As an important regulator of the cell cycle, Skp2 can specifically recognize phosphorylated substrates and perform ubiquitin-mediated degradation. p21 is one of the substrates of the ubiquitin proteasome pathway; it is phosphorylated at the Ser-130 site with the participation of CDK2-cyclin E and enters the ubiquitin degradation pathway under the action of the accessory protein, CKS1 (43).
In addition, affecting mRNA stability and the control of the translation of p21 mRNA are also an important part of the p21 post-transcriptional regulatory mechanism. In 2017, Li et al (44) silenced methyltransferases (NSUN2, METTL3 or METTL14) and found that the protein level of p21 decreased, although its mRNA expression was not altered; thus, they came to the conclusion that NSUN2, METTL3 and METTL14 may affect p21 expression levels by regulating p21 translation. Another study found that HuR and AUF1 may competitively bind with the p21 3'-untranslated region and regulate p21 mRNA stability (45). These two RNA-binding proteins competitively bind to $\mathrm{p} 21 \mathrm{mRNA}$, but lead to opposite results; HuR can enhance the stability of mRNA, while AUF1 accelerates p21 mRNA decay. The regulation of p21 mRNA and protein stability has not yet been extensively investigated in EC cells. The aim of the present review was mainly to explain the diversity of the mechanisms implicated in the regulation of p21 and the key role of p21 in complex networks. The aforementioned regulation mechanism is shown in detail in Fig. 2.

\section{Role of p21 in the treatment of esophageal cancer}

p21 holds promise as a prognostic indicator and for the evaluation of treatment efficacy. From the aforementioned description of the function of $\mathrm{p} 21$ and its regulatory mechanisms, it may be inferred that p21 is a key regulatory factor in EC; thus, the study of p21 is of utmost clinical significance. In fact, some studies have confirmed that p21 plays an important role in the prognosis of EC. A previous meta-analysis revealed that a low p21 expression was associated with clinicopathological characteristics such as poor differentiation, lymph node metastasis, aggressiveness, higher grade and clinical stage, which are associated with a poor outcome of patients with EC (46). Apart from this latter study, there is ample evidence indicating that high expression of p21 is an important indicator of good prognosis for patients with EC (47-49). These studies suggested that low p21 expression is an indicator of a highly malignant EC. The expression of p21 is often regulated by p53; thus, comprehensive consideration is needed when determining the prognosis of patients with EC. A previous study demonstrated that, in p53-positive patients with EC, the expression of p21 exerted no significant effect on the survival rate of the patients; however, the survival rate of patients with p21-positive tumors was significantly higher compared with that of patients with p21-negative tumors (50). 


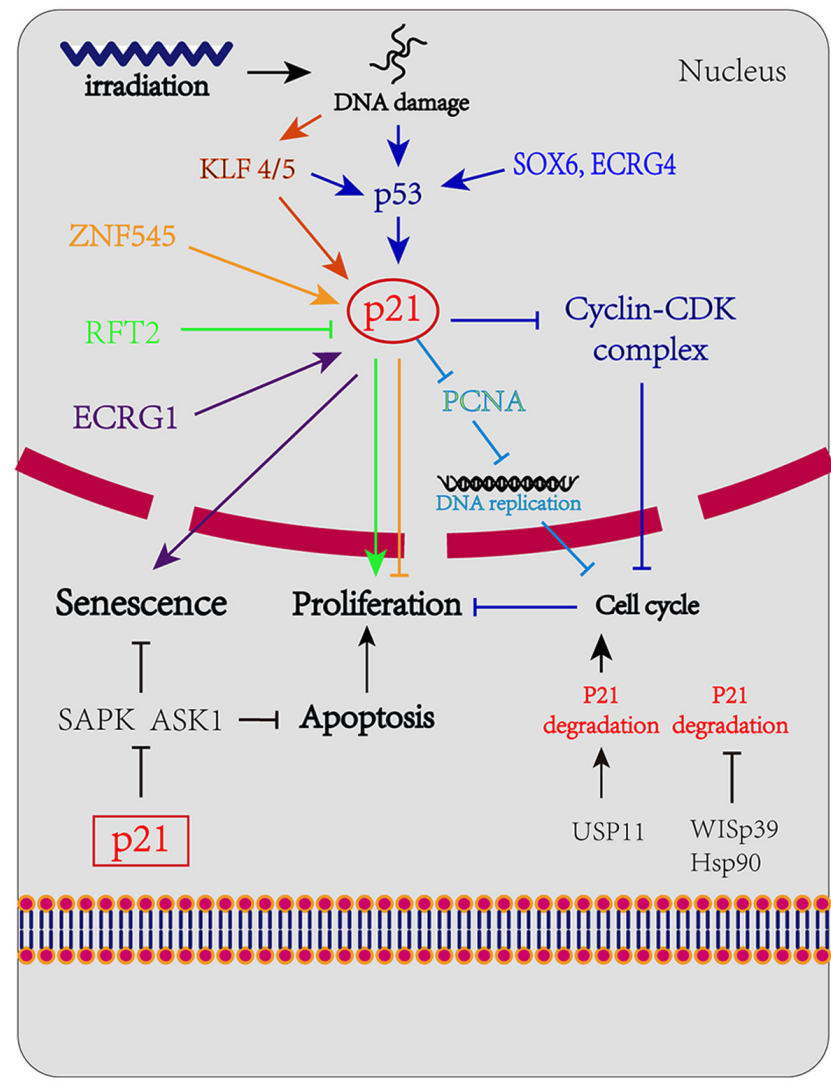

Figure 2. p21 is regulated by multiple pathways. It was found that p21 is a key factor in esophageal cancer cells. Through the control of $\mathrm{p} 21$, the regulation of cell proliferation, senescence and apoptosis may be achieved. The pathway indicated by the black line has not been confirmed in esophageal cancer cells. The main purpose was to highlight the double-sidedness of $\mathrm{p} 21$, and this double-sidedness is often associated with the localization of p21 in the cell.

The combination of chemotherapy and radiotherapy is the main treatment strategy for advanced EC. The expression of p53 and p21 has been proven to be an indicator of the efficacy of radiotherapy and chemotherapy $(47,50,51)$ for ESCC as well as EADC. As shown in Fig. 3, a previous study indicated that the change in the p21 status from negative to positive during treatment was accompanied by an improvement in survival (52).

At present, p21 is known to play an important role in a variety of cancers and cannot be considered as a specific marker for the diagnosis of EC. However, p21 is important for evaluating prognosis and treatment efficacy in patients with EC.

\section{p21 as a novel target for EC treatment}

CDK4/6 inhibitors in clinical treatment. p21 is a classic cell cycle regulator that acts as a gene downstream of p53 to block the progression of the cell cycle. This provides a basis for its use as a target for cancer treatment. In fact, antitumor therapy targeting the cell cycle has gradually matured. Some antitumor drugs targeting the cell cycle have entered clinical practice, such as palbociclib, abemaciclib and ribociclib (53). Palbociclib is an oral targeted drug that directly acts on CDK4/6 and inhibits its function, thereby restoring cell cycle control and inhibiting tumor cell proliferation (54). At present, CDK4/6 inhibitors are only approved for the treatment of ER-positive breast cancer and attempts are being made to further expand their use. Moreover, the identification of a novel target for EC is required. The present review aimed to address the possibility of using p21 as a novel therapeutic target.

Drugs targeting p21 exert therapeutic effects on EC. Some drugs in trials have been shown to promote p21 expression, thereby inhibiting EC cell growth. A number of drugs targeting p21 are currently under development. Diallyl disulfide (DADS) is a lipid-soluble organic compound derived from garlic. A previous study used various concentrations of DADS to treat cells, and found that the proportion of EC cells in the $G_{2} / M$ phase continued to increase, and the mRNA level of p21 also increased with increasing DADS concentration. The same study confirmed that DADS was an effective anticancer drug by suppressing cell viability, blocking the cell cycle at the $\mathrm{G}_{2} / \mathrm{M}$ phase and inducing the apoptosis of EC cells (55). Molecular analysis revealed that cell cycle arrest may be due to the reduction of cyclin B1, cdc2, p-cdc2 and cdc25c, and the activation of the p53/p21 pathway. DADS was shown to activate caspases, alter the $\mathrm{Bax} / \mathrm{Bcl}-2$ balance and inhibit the MEK/ERK pathway to induce apoptosis (55).

Another study found that obatoclax (a type of BH3-mimetic) induced $\mathrm{G}_{1} / \mathrm{G}_{0}$ arrest of $\mathrm{EC}$ cells through the p38/p21 signaling pathway. Obatoclax is an indole bipyrrole compound that can inhibit all known antiapoptotic Bcl-2 family members. Obatoclax did not alter the expression of CDKs, including CDK2, CDK4 and CDK6, but significantly increased the protein level of the CDK inhibitor, p21. The findings of that study may shed new light on the anticancer activity of obatoclax and its potential application in clinical practice (56).

Cinobufagin, isolated from traditional Chinese herbs, exerts antitumor, anesthetic, analgesic and anti-inflammatory effects. A previous study by Deng et al (57) indicated that cinobufagin induced ESCC cell cycle arrest at the $G_{2} / M$ phase and promoted apoptosis by regulating the expression of $\mathrm{p} 21$, indicating that traditional Chinese medicine may prove useful for the treatment of EC.

Combined use of drugs targeting p21 can enhance the sensitivity to radiotherapy and chemotherapy. It was recently reported that crocetin combined with cisplatin exert a synergistic anti-ESCC effect by upregulating the p53/p21 pathway. The researchers demonstrated that the combination of crocetin and cisplatin treatment markedly affected the expression of p53 and p21 compared with treatment with cisplatin alone. This type of combined treatment inhibited KYSE-150 cell proliferation and promoted cell apoptosis in vitro (58).

Liu et al (59) demonstrated that Antrodia cinnamomea mycelial fermentation broth blocked the cell cycle progression of EC cells in the $\mathrm{G}_{2} / \mathrm{M}$ phase by upregulating the expression of p21, thus rendering the cells more sensitive to the subsequent dose of radiation. The aforementioned simple examples demonstrate that $\mathrm{p} 21$-regulated drugs have exhibited potent antitumor effects in experiments; a number of other studies have also proven this effect $(58,60-67)$. The mechanisms of some of these drugs are summarized in Table II. 
Table II. Substances used to treat esophageal cancer by regulating p21 expression in previous experiments.

\begin{tabular}{ll}
\hline Substance & \multicolumn{1}{c}{ Mechanism } \\
\hline DADS & p53/p21 pathway \\
Obatoclax & p38/p21 pathway \\
Cinobufagin & p73/p21 pathway \\
Crocetin & p53/p21 pathway \\
AC-MFB & Upregulation of p21 expression \\
Ruthenium (II) complex & p53/p21 pathway \\
Costunolide & p53/p21 pathway \\
Oridonin & p53/p21 pathway \\
Licochalone C & Upregulation of $221 / \mathrm{p} 27$ expression \\
Suberoylanilide hydroxamic acid & Upregulation of p21/p27/Rb expression \\
Tanshinone IIA & p53/p21 pathway \\
Thymoquinone & p53/p21 pathway \\
\hline
\end{tabular}

DADS, diallyl disulfide; AC-MFB, Antrodia cinnamomea mycelial fermentation broth.

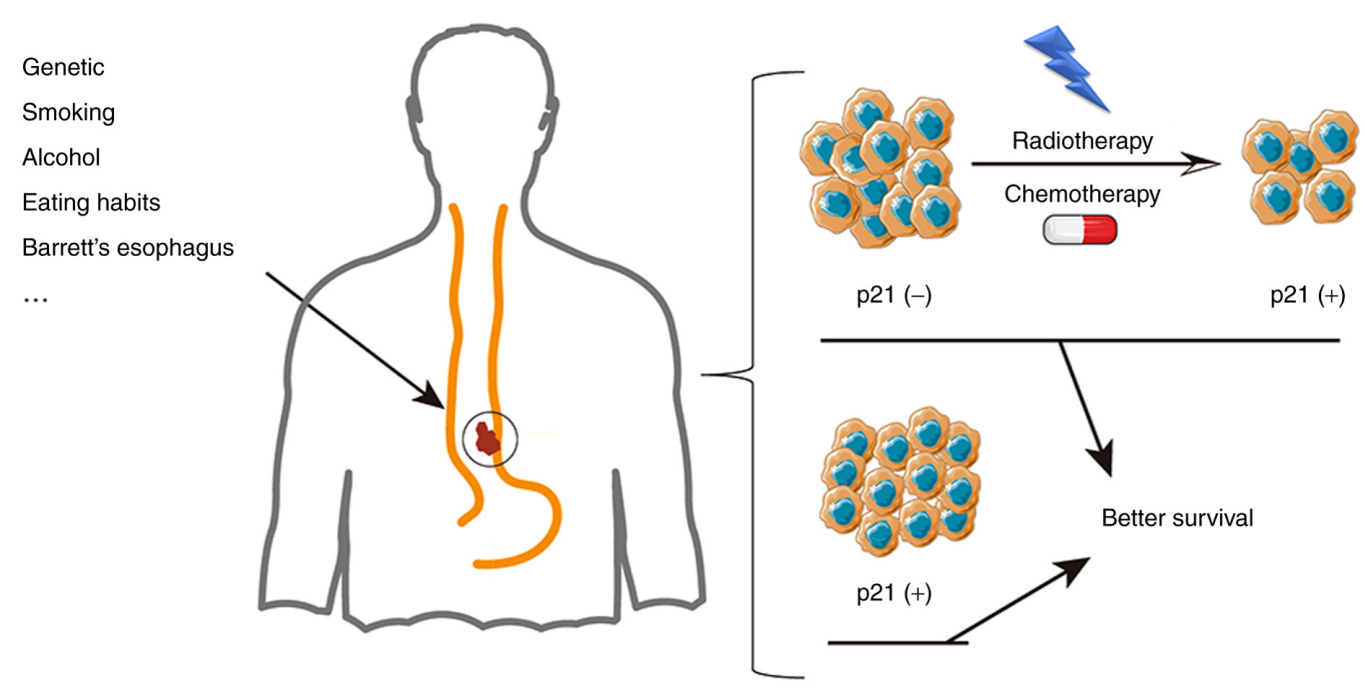

Figure 3. A number of pathogenic factors are implicated in esophageal cancer. Hereditary and daily living habits are considered as the main carcinogenic factors. Barrett's esophagus is a high-risk factor for esophageal adenocarcinoma. Previous studies have demonstrated that a high expression of p21 is an indicator of a favorable prognosis for patients with esophageal cancer. Following treatment, the expression of p21 changes from negative to positive, which also indicates a favorable prognosis.

\section{Conclusion}

The therapeutic potential of p21 in EC warrants further investigation. At present, the drugs targeting p21 have not been used in clinical practice. All of the aforementioned agents have been proven effective in the treatment of EC in vitro. These drugs cause cell cycle arrest and induce apoptosis by increasing the expression of p21. Furthermore, some substances obtained from Chinese medicine have been shown to exert therapeutic effects on EC, which also proves the value of Chinese medicine in antitumor therapy (57).

It has been previously indicated that patients with p21-deficient EC have a shorter survival time (46). For this group of patients, it would be of interest to determine whether a type of p21 analog could be produced in order to take advantage of the tumor-suppressive effects of p21. Similar to the use of p16 as a template for the development of palbociclib, a similar drug may be created using p21 as the template. To date, there is no study available on p21 analogues, at least to the best of our knowledge. If $\mathrm{p} 21$ protein analogs can be developed to regulate the cycle of EC cells, this may benefit a greater number of patients with EC.

Georgakilas et al (15) described p21 as a 'two-faced genome guardian'; this indicates that it has different functions in different conditions in tumors. In the absence of p53, the long-term overexpression of p21 enables some cells to escape senescence (68). There are a number of difficulties encountered in the identification of the mechanisms of p21 due to its multiple roles. However, current research indicates that p21 mainly plays a role in inhibiting cell proliferation in EC. In addition, the prognosis of patients with EC can be evaluated and the efficacy of chemotherapy and radiotherapy can be determined by detecting the expression of p21 (69). Thus, investigating the mechanism of p21 in EC should be the focus of future research. If $\mathrm{p} 21$ can be used as a prognostic indicator 
for EC, the treatment efficacy of EC may improve, and more patients will reap the benefits.

\section{Acknowledgements}

Not applicable.

\section{Funding}

The present study was supported by the National Natural Science Foundation of China (grant no. 81872264).

\section{Availability of data and materials}

Not applicable.

\section{Authors' contributions}

LW and $\mathrm{HH}$ were involved in designing the study, in the literature review and in the drafting of the manuscript. LW was also responsible for designing the figures. $\mathrm{LD}$ and $\mathrm{ZW}$ participated in the acquisition and analysis of data, and in the discussion of the manuscript. YQ designed the study and critically revised the manuscript. All the authors have read and approved the final version of the manuscript.

\section{Ethics approval and consent to participate}

Not applicable.

\section{Patient consent for publication}

Not applicable.

\section{Competing interests}

The authors declare that they have no competing interests.

\section{References}

1. Bray F, Ferlay J, Soerjomataram I, Siegel RL, Torre LA and Jemal A: Global cancer statistics 2018: GLOBOCAN estimates of incidence and mortality worldwide for 36 cancers in 185 countries. CA Cancer J Clin 68: 394-424, 2018.

2. Qu X, Ben Q and Jiang Y: Consumption of red and processed meat and risk for esophageal squamous cell carcinoma based on a meta-analysis. Ann Epidemiol 23: 762-770.e1, 2013.

3. Prabhu A, Obi KO and Rubenstein JH: The synergistic effects of alcohol and tobacco consumption on the risk of esophageal squamous cell carcinoma: A meta-analysis. Am J Gastroenterol 109: 822-827, 2014.

4. Andrici J and Eslick GD: Hot food and beverage consumption and the risk of esophageal cancer: A meta-analysis. Am J Prev Med 49: 952-960, 2015.

5. Wu C, Wang Z, Song X, Feng XS, Abnet CC, He J, Hu N, Zuo XB, Tan $\mathrm{W}$, Zhan $\mathrm{Q}$, et al: Joint analysis of three genome-wide association studies of esophageal squamous cell carcinoma in Chinese populations. Nat Genet 46: 1001-1006, 2014.

6. Wang SM, Abnet CC and Qiao YL: What have we learned from Linxian esophageal cancer etiological studies? Thorac Cancer 10: 1036-1042, 2019.

7. Spechler SJ: Barrett's esophagus. Curr Opin Gastroenterol 15: 352-358, 1999.

8. Woodward TA, Klingler PD, Genko PV and Wolfe JT: Barrett's esophagus, apoptosis and cell cycle regulation: Correlation of p53 with Bax, Bcl-2 and p21 protein expression. Anticancer Res 20: 2427-2432, 2000.
9. Hong Y and Ding ZY: PD-1 inhibitors in the advanced esophageal cancer. Front Pharmacol 10: 1418, 2019.

10. Pennathur A, Gibson MK, Jobe BA and Luketich JD: Oesophageal carcinoma. Lancet 381: 400-412, 2013.

11. el-Deiry WS, Tokino T, Velculescu VE, Levy DB, Parsons R, Trent JM, Lin D, Mercer WE, Kinzler KW and Vogelstein B: WAF1, a potential mediator of p53 tumor suppression. Cell 75: 817-825, 1993.

12. Harper JW, Adami GR, Wei N, Keyomarsi K and Elledge SJ: The p21 Cdk-interacting protein Cip1 is a potent inhibitor of G1 cyclin-dependent kinases. Cell 75: 805-816, 1993.

13. Petroni G, Formenti SC, Chen-Kiang S and Galluzzi L: Immunomodulation by anticancer cell cycle inhibitors. Nat Rev Immunol 20: 669-679, 2020.

14. Zhang Y, Miao Y, Shang M, Liu M, Liu R, Pan E, Pu Y and Yin L: LincRNA-p21 leads to G1 arrest by p53 pathway in esophageal squamous cell carcinoma. Cancer Manag Res 11: 6201-6214, 2019.

15. Georgakilas AG, Martin OA and Bonner WM: p21: A two-faced genome guardian. Trends Mol Med 23: 310-319, 2017.

16. Evans T, Rosenthal ET, Youngblom J, Distel D and Hunt T: Cyclin: A protein specified by maternal mRNA in sea urchin eggs that is destroyed at each cleavage division. Cell 33: 389-396, 1983.

17. Bloom J and Cross FR: Multiple levels of cyclin specificity in cell-cycle control. Nat Rev Mol Cell Biol 8: 149-160, 2007.

18. LaBaer J, Garrett MD, Stevenson LF, Slingerland JM, Sandhu C, Chou HS, Fattaey A and Harlow E: New functional activities for the p21 family of CDK inhibitors. Genes Dev 11: 847-862, 1997.

19. Waga S and Stillman B: The DNA replication fork in eukaryotic cells. Annu Rev Biochem 67: 721-751, 1998.

20. Celis JE, Madsen P, Celis A, Nielsen HV and Gesser B: Cyclin (PCNA, auxiliary protein of DNA polymerase delta) is a central component of the pathway(s) leading to DNA replication and cell division. FEBS Lett 220: 1-7, 1987.

21. Podust VN, Podust LM, Goubin F, Ducommun B and Hübscher U: Mechanism of inhibition of proliferating cell nuclear antigen-dependent DNA synthesis by the cyclin-dependent kinase inhibitor p21. Biochemistry 34: 8869-8875, 1995.

22. Waga S, Hannon GJ, Beach D and Stillman B: The p21 inhibitor of cyclin-dependent kinases controls DNA replication by interaction with PCNA. Nature 369: 574-578, 1994.

23. Zhang H, Xiong Y and Beach D: Proliferating cell nuclear antigen and p21 are components of multiple cell cycle kinase complexes. Mol Biol Cell 4: 897-906, 1993.

24. Asada M, Yamada T, Ichijo H, Delia D, Miyazono K, Fukumuro K and Mizutani S: Apoptosis inhibitory activity of cytoplasmic p21(Cip1/WAF1) in monocytic differentiation. EMBO J 18: 1223-1234, 1999.

25. Tanaka H, Yamashita T, Asada M, Mizutani S, Yoshikawa H and Tohyama M: Cytoplasmic p21(Cip1/WAF1) regulates neurite remodeling by inhibiting Rho-kinase activity. J Cell Biol 158: 321-329, 2002.

26. Zhan J, Easton JB, Huang S, Mishra A, Xiao L, Lacy ER, Kriwacki RW and Houghton PJ: Negative regulation of ASK1 by p21Cip1 involves a small domain that includes Serine 98 that is phosphorylated by ASK1 in vivo. Mol Cell Biol 27: 3530-3541, 2007.

27. Xiong Y, Hannon GJ, Zhang H, Casso D, Kobayashi R and Beach D: p21 is a universal inhibitor of cyclin kinases. Nature 366: 701-704, 1993.

28. Liu S, Bishop WR and Liu M: Differential effects of cell cycle regulatory protein $\mathrm{p} 21(\mathrm{WAF} 1 / \mathrm{Cip} 1)$ on apoptosis and sensitivity to cancer chemotherapy. Drug Resist Updat 6: 183-195, 2003.

29. Kim J, Bae S, An S, Park JK, Kim EM, Hwang SG, Kim WJ and Um HD: Cooperative actions of p21WAF1 and p53 induce Slug protein degradation and suppress cell invasion. EMBO Rep 15: 1062-1068, 2014

30. Kim EM, Jung CH, Kim J, Hwang SG, Park JK and Um HD: The p53/p21 complex regulates cancer cell invasion and apoptosis by targeting Bcl-2 family proteins. Cancer Res 77: 3092-3100, 2017.

31. Lu F, Chen H, Zhou C, Liu S, Guo M, Chen P, Zhuang H, Xie D and $\mathrm{Wu} \mathrm{S}$ : T-type $\mathrm{Ca} 2+$ channel expression in human esophageal carcinomas: A functional role in proliferation. Cell Calcium 43: 49-58, 2008.

32. Li H, Zheng D, Zhang B, Liu L, Ou J, Chen W, Xiong S, Gu Y and Yang J: Mir-208 promotes cell proliferation by repressing SOX6 expression in human esophageal squamous cell carcinoma. J Transl Med 12: 196, 2014.

33. Li L, Zhang C, Li X, Lu S and Zhou Y: The candidate tumor suppressor gene ECRG4 inhibits cancer cells migration and invasion in esophageal carcinoma. J Exp Clin Cancer Res 29: 133, 2010. 
34. Qin YR, Tang H,Xie F, Liu H,Zhu Y, Ai J, Chen L, Li Y,Kwong DL, Fu L and Guan XY: Characterization of tumor-suppressive function of SOX6 in human esophageal squamous cell carcinoma. Clin Cancer Res 17: 46-55, 2011

35. Yang Y, Goldstein BG, Chao HH and Katz JP: KLF4 and KLF5 regulate proliferation, apoptosis and invasion in esophageal cancer cells. Cancer Biol Ther 4: 1216-1221, 2005.

36. Fan Y, Wang Y, Fu S, Liu D and Lin S: Methylation-regulated ZNF545 inhibits growth of the p53-mutant KYSE150 cell line by inducing p21 and Bax. Exp Ther Med 18: 1563-1570, 2019.

37. Jiang XR, Yu XY, Fan JH, Guo L, Zhu C, Jiang W and Lu SH RFT2 is overexpressed in esophageal squamous cell carcinoma and promotes tumorigenesis by sustaining cell proliferation and protecting against cell death. Cancer Lett 353: 78-86, 2014.

38. Zhao N, Huang G, Guo L and Lu SH: ECRG1, a novel candidate of tumor suppressor gene in the esophageal carcinoma triggers a senescent program in NIH3T3 cells. Exp Biol Med (Maywood) 231: 84-90, 2006.

39. Jascur T, Brickner H, Salles-Passador I, Barbier V, El Khissiin A, Smith B, Fotedar R and Fotedar A: Regulation of p21(WAF1/CIP1) stability by WISp39, a Hsp90 binding TPR protein. Mol Cell 17: 237-249, 2005

40. Liu G and Lozano G: p21 stability: Linking chaperones to a cell cycle checkpoint. Cancer Cell 7: 113-114, 2005

41. Deng T, Yan G, Song X, Xie L, Zhou Y, Li J, Hu X, Li Z, Hu J, Zhang Y, et al: Deubiquitylation and stabilization of p21 by USP11 is critical for cell-cycle progression and DNA damage responses. Proc Natl Acad Sci USA 115: 4678-4683, 2018.

42. Wang W, Nacusi L, Sheaff RJ and Liu X: Ubiquitination of p21Cip1/WAF1 by SCFSkp2: Substrate requirement and ubiquitination site selection. Biochemistry 44: 14553-14564, 2005.

43. Bornstein G, Bloom J, Sitry-Shevah D, Nakayama K, Pagano M and Hershko A: Role of the SCFSkp2 ubiquitin ligase in the degradation of p21Cip1 in S phase. J Biol Chem 278: 25752-25757, 2003.

44. Li Q, Li X, Tang H, Jiang B, Dou Y, Gorospe M and Wang W: NSUN2-mediated m5C methylation and METTL3/METTL14 mediated m6A methylation cooperatively enhance p21 translation. J Cell Biochem 118: 2587-2598, 2017.

45. Lal A, Mazan-Mamczarz K, Kawai T, Yang X, Martindale JL and Gorospe M: Concurrent versus individual binding of HuR and AUF1 to common labile target mRNAs. EMBO J 23: 3092-3102, 2004.

46. Wu J, Liu L, Wu F, Qiu L, Luo M, Ke Q, Deng X and Luo Z: Clinical and prognostic implications of P21 (WAF1/CIP1) expression in patients with esophageal cancer: A systematic review and meta-analysis. Dis Markers 2020: 6520259, 2020

47. Ishida M, Morita M, Saeki H, Ohga T, Sadanaga N, Watanabe M, Kakeji Y and Maehara Y: Expression of p53 and p21 and the clinical response for hyperthermochemoradiotherapy in patients with squamous cell carcinoma of the esophagus. Anticancer Res 27: 3501-3506, 2007.

48. Kuwahara M, Hirai T, Yoshida K, Yamashita Y, Hihara J, Inoue H and Toge T: p53, p21(Waf1/Cip1) and cyclin D1 protein expression and prognosis in esophageal cancer. Dis Esophagus 12: $116-119,1999$

49. Lin Y, Shen LY, Fu H, Dong B, Yang HL, Yan WP, Kang XZ, Dai L, Zhou HT, Yang YB, et al: P21, COX-2, and E-cadherin are potential prognostic factors for esophageal squamous cell carcinoma. Dis Esophagus 30: 1-10, 2017

50. Nakamura T, Hayashi K, Ota M, Ide H, Takasaki K and Mitsuhashi M: Expression of p21(Waf1/Cip1) predicts response and survival of esophageal cancer patients treated by chemoradiotherapy. Dis Esophagus 17: 315-321, 2004

51. Sohda M, Ishikawa H, Masuda N, Kato H, Miyazaki T, Nakajima M, Fukuchi M, Manda R, Fukai Y, Sakurai $\mathrm{H}$ and Kuwano H: Pretreatment evaluation of combined HIF-1alpha, p53 and p21 expression is a useful and sensitive indicator of response to radiation and chemotherapy in esophageal cancer. Int J Cancer 110: 838-844, 2004

52. Heeren PA, Kloppenberg FW, Hollema H, Mulder NH, Nap RE and Plukker JT: Predictive effect of p53 and p21 alteration on chemotherapy response and survival in locally advanced adenocarcinoma of the esophagus. Anticancer Res 24: 2579-2883, 2004

53. Ingham $M$ and Schwartz GK: Cell-cycle therapeutics come of age. J Clin Oncol 35: 2949-2959, 2017.
54. Clark AS, Karasic TB, DeMichele A, Vaughn DJ, O'Hara M, Perini R,Zhang P,LalP, Feldman M, GallagherM and O'Dwyer PJ: Palbociclib (PD0332991)-a selective and potent cyclin-dependent kinase inhibitor: A review of pharmacodynamics and clinical development. JAMA Oncol 2: 253-260, 2016.

55. Yin X, Zhang R, Feng C, Zhang J, Liu D, Xu K, Wang X, Zhang S, Li Z, Liu X and Ma H: Diallyl disulfide induces G2/M arrest and promotes apoptosis through the p53/p21 and MEK-ERK pathways in human esophageal squamous cell carcinoma. Oncol Rep 32: 1748-1756, 2014.

56. Zhong D, Gu C, Shi L, Xun T, Li X, Liu S and Yu L: Obatoclax induces G1/G0-phase arrest via p38/p21(waf1/Cip1) signaling pathway in human esophageal cancer cells. J Cell Biochem 115: 1624-1635, 2014

57. Deng X, Sheng J, Liu H, Wang N, Dai C, Wang Z, Zhang J, Zhao J and Dai E: Cinobufagin promotes cell cycle arrest and apoptosis to block human esophageal squamous cell carcinoma cells growth via the p73 signalling pathway. Biol Pharm Bull 42: $1500-1509,2019$

58. Li S, Shen XY, Ouyang T, Qu Y, Luo $\mathrm{T}$ and Wang HQ: Synergistic anticancer effect of combined crocetin and cisplatin on KYSE-150 cells via p53/p21 pathway. Cancer Cell Int 17: 98 , 2017.

59. Liu YM, Liu YK, Huang PI, Tsai TH and Chen YJ: Antrodia cinnamomea mycelial fermentation broth inhibits the epithelial-mesenchymal transition of human esophageal adenocarcinoma cancer cells. Food Chem Toxicol 119: 380-386, 2018.

60. Guo L, Lv G, Qiu L, Yang H, Zhang L, Yu H, Zou M and Lin J: Insights into anticancer activity and mechanism of action of a ruthenium(II) complex in human esophageal squamous carcinoma EC109 cells. Eur J Pharmacol 786: 60-71, 2016.

61. Hua P, Sun M, Zhang G, Zhang Y, Song G, Liu Z, Li X, Zhang X and $\mathrm{Li} \mathrm{B}$ : Costunolide induces apoptosis through generation of ROS and activation of P53 in human esophageal cancer Eca-109 cells. J Biochem Mol Toxicol 30: 462-469, 2016

62. Jiang JH, Pi J, Jin H and Cai JY: Oridonin-induced mitochondria-dependent apoptosis in esophageal cancer cells by inhibiting PI3K/AKT/mTOR and Ras/Raf pathways. J Cell Biochem 120: 3736-3746, 2019

63. Kwak AW, Choi JS, Liu K, Lee MH, Jeon YJ, Cho SS, Yoon G, Oh HN, Chae JI and Shim JH: Licochalcone C induces cell cycle G1 arrest and apoptosis in human esophageal squamous carcinoma cells by activation of the ROS/MAPK signaling pathway. J Chemother 32: 132-143, 2020.

64. Liu YM, Liu YK, Wang LW, Huang YC, Huang PI, Tsai TH and Chen YJ: The medicinal fungus Antrodia cinnamomea regulates DNA repair and enhances the radiosensitivity of human esophageal cancer cells. Onco Targets Ther 9: 6651-6661, 2016.

65. Tzao C, Jin JS, Chen BH, Chung HY, Chang CC, Hsu TY and Sun GH: Anticancer effects of suberoylanilide hydroxamic acid in esophageal squamous cancer cells in vitro and in vivo. Dis Esophagus 27: 693-702, 2014.

66. Wang JF, Feng JG, Han J, Zhang BB and Mao WM: The molecular mechanisms of Tanshinone IIA on the apoptosis and arrest of human esophageal carcinoma cells. Biomed Res Int 2014: 582730,2014

67. Ma J, Zhang Y, Deng H, Liu Y, Lei X, He P, Dong W: Thymoquinone inhibits the proliferation and invasion of esophageal cancer cells by disrupting the AKT/GSK-3 $\beta /$ Wnt signaling pathway via PTEN upregulation. Phytother Res: Sep 9, 2020 (Epub ahead of print). doi: 10.1002/ptr.6795.

68. Galanos P, Vougas K, Walter D, Polyzos A, Maya-Mendoza A, Haagensen EJ, Kokkalis A, Roumelioti FM, Gagos S, Tzetis M, et al: Chronic p53-independent p21 expression causes genomic instability by deregulating replication licensing. Nat Cell Biol 18: 777-789, 2016

69. El-Deiry WS: p21(WAF1) mediates cell-cycle inhibition, relevant to cancer suppression and therapy. Cancer Res 76: 5189-5191, 2016.

This work is licensed under a Creative Common Attribution-NonCommercial-NoDerivatives 4.0 International (CC BY-NC-ND 4.0) License. 